\title{
The effect of an invasive bryozoan on community diversity and structure varies across two locations
}

\author{
Z. R. Scott ${ }^{1}$ and C. P. terHorst \\ Department of Biology, California State University, Northridge, Northridge, CA 91330-8303, USA \\ ${ }^{1}$ Corresponding author. Email: zscott@sandiego.gov
}

Keywords: Community structure; Diversity; Ecological community; Environmental variation; Foundation species; Watersipora subtorquata.

\begin{abstract}
Foundation species and invasive species strongly influence community diversity and structure, but typically in different ways. However, when widespread invasive species provide novel habitat within a community, their net effect may depend on both the environment and community composition. Fouling communities in northern and southern California harbors were surveyed to determine whether there was variation between two locations in the percent cover of an invasive bryozoan, Watersipora subtorquata (d'Orbigny, 1852), and its relationship to community diversity and composition in these two environments. Diversity significantly differed between locations and had a location-dependent association with W. subtorquata abundance. Communities were significantly dissimilar between locations, and $W$. subtorquata abundance had the highest percent contribution to community dissimilarity when compared to other species in the community. These results suggest that invasive species may have both facilitative and inhibitive relationships with species in a community, but that the net balance of these interactions depends on both the environmental and community context.
\end{abstract}

Abbreviations: AIC - Akaike Information Criterion; GLMM - Generalized Linear Mixed Model; nMDS - nonmetric Multidimensional Scaling; PERMANOVA - Permutational Analysis of Variance; SIMPER - Similarity Percentage.

\section{Introduction}

Though communities are composed of many species, a persistent challenge for ecologists is determining which species have the greatest influence on community structure through direct and indirect cascading effects. Furthermore, understanding how the presence and abundance of influential species affects the interactions with other community members is vital to characterizing the net impact on the community. Three examples of species that can greatly influence communities include keystone species, foundation species, and invasive species. While keystone species can have relatively little biomass in a community relative to their disproportionately large impact (Power et al. 1996), foundation species and invasive species typically comprise a larger biomass relative to their effects on the community. Though foundation species and invasive species can both dominate the communities they inhabit, where they may differ is in their net effects on communities that result from positive and negative interactions with its members (Rodriguez 2006, Hughes 2010). Foundation species, such as corals (Holbrook et al. 2008), trees (Rohr et al. 2009, Angelini and Silliman 2014), and kelps (Graham 2004, Hughes 2010), which can dominate the landscape, generally have positive effects on species diversity by increasing habitat complexity (Stachowicz 2001, Bruno et al. 2003). Through their net positive interactions with other species, foundation species increase structural habitat heterogeneity and complexity, facilitate greater community diversity, and increase ecosystem function (Dayton and Hessler 1972, Stachowicz and Byrnes 2006).

Invasive species, by definition, overcome biotic and abiotic filters to survival, spread and establish populations, and have some measurable effect on the communities they inhabit (Lockwood et al. 2013). Either directly via competition or predation, or indirectly by altering the physical or biotic environment (Bax et al. 2003, Sorte et al. 2010), invasive species can cause a net decline in species diversity, though these effects may vary across established populations in their invasive range (Colautti and MacIsaac 2004). Invasive species such as the macroalga Gracilaria vermiculophylla (Willette and Ambrose 2012, Thomsen et al. 2013) and salt cedar Tamarix spp. (York et al. 2011) can displace native species and reduce diversity to a few species with high biomass relative to noninvaded communities. In marine communities where available settlement substrate is at a premium, fast-growing species like Didemnum sp. have invaded and outcompeted native fouling invertebrate species for space, decreasing community diversity and negatively impacting the mussel industry (Gittenberger 2007, 2009). Traits linked with invasiveness, such as fast growth rates (Van Kleunen et al. 2010, Graebner et al. 2012), high colonization potential (Lord et al. 2015), and adaptability to different environments (Sorte et al. 2010), 
also increase the ability of invasive species to displace native species. However, in some cases, invasive species can create or modify habitat for other species, serving as foundation species that increase habitat complexity and species diversity. For example, Zostera japonica-a widely-introduced east Asian seagrass along the western North American coast-is associated with higher invertebrate abundance and facilitation of species diversity as its shoot density and morphology create greater structural complexity relative to the native congener, Zostera marina (Posey 1988, Knight et al. 2015). This and other algal species have been found to have negative effects on other algal species in the community, but neutral or positive effects on animal communities through habitat formation, food provision, and cascading habitat formation (Thomsen et al. 2016).

Invasive species often occupy wide ranges and encounter different environments and community members during their range expansion. Since species interactions strengths are often dependent on the environmental context in which the interactions occur (Bertness and Callaway 1994), the net effect of invasive species on the community may be contextdependent. The success of an invader depends on its ability to pass through ecological filters of both abiotic factors and biotic interactions (Crowl et al. 2008). The successful settlement and growth of invaders may vary across environmental gradients of temperature (Stachowicz et al. 2002), resource availability (Stachowicz and Byrnes 2006), or intensities of competition and predation (Levine et al. 2004, Lord 2016). Habitat provided by foundation species, while beneficial for species that use the biogenic habitat as refuge from predation, may increase competition for space among other species, and invaders that provide novel habitat within a community may have cascading indirect effects on composition and diversity (Simberloff 1995, Parker et al. 1999, Crooks 2002). Therefore, the net balance of positive and negative interactions between the invader and its community members depends on the strength of ecological filters, its response to these filters, and the response of other species in the community to the invader.

Invasive species in invertebrate marine fouling communities often spread across wide ranges because of long dispersal by larvae, commonly aided by global anthropogenic transportation of propagules. Introductions occur frequently (Lord 2016), but communities vary in the timing of seasonal peaks in propagule supply (Cifuentes et al. 2010) and the degree of competition for space (Edwards and Stachowicz 2012). As such, fouling communities are useful systems for studying species interactions and diversity since the limited resource of settlement substrate promotes a colonization-competition tradeoff in life history traits of community members (Edwards and Stachowicz 2010). Bryozoans are common invertebrate invaders in fouling communities largely due to their abundance in ship ballast water and ability to settle and grow on ship hulls (Mackie et al. 2012), marine debris such as crates or totes (McCuller and Carlton 2018), and other artificial substrates (Miranda et al. 2018), and transport via the movement of commercial shellfish (Carlton 2009). Their shared characteristics (e.g., introduction vector, brooded offspring, vegeta- tive asexual growth, global distribution) with other invasive fouling species of harbors and bays such as Bugula neritina (Bryozoa, Linnaeus, 1758), Botrylloides violaceus (Chordata, Oka, 1927), and Didemnum vexillum (Chordata, Kott, 2002) make them useful model organisms for generalizing results to other colonial invertebrates (Mackie et al. 2006, Mckenzie et al. 2012). Byrozoans start as brooded larvae that, once settled onto substrate, metamorphose into the first zooid (i.e., ancestrula), and grow asexually, budding zooids to form colonies with varying morphology and complexity. Colonies can either be flat and encrusting with little structural complexity, or upright and foliose or branching, which have higher complexity and heterogeneity (Ryland and Hayward 1991).

Watersipora subtorquata (d'Orbigny, 1852) is an invasive bryozoan with cryptogenic origins in the eastern Atlantic that is found on the West coast of the United States, Hawaii, Australia, New Zealand, Europe, and South Africa (Vieira et al. 2014). This colonial invertebrate may serve as a foundation species for small $(\leq 2 \mathrm{~cm})$ invertebrates (Floerl et al. 2004, Stachowicz et al. 2007), but also competes strongly with other fouling species (e.g., cnidarians, ascidians, sponges, bivalves) for space (Sellheim et al. 2009) and has a strong overgrowth capability relative to other fouling community members (Edwards and Stachowicz 2010). Traits such as metal tolerance (McKenzie et al. 2011), fast growth (Vieira et al. 2014), and successful settlement across different environmental conditions (Mackie et al. 2006) have allowed $W$. subtorquata to successfully invade a broad range of temperature and salinity environments (Wyatt et al. 2005, Zerebecki and Sorte 2011).

W. subtorquata has been associated with increased diversity of polychaetes and crustaceans within Bodega Harbor, CA (Sellheim et al. 2009), partly due to its greater heterogeneity compared to other habitat providers (e.g., mussels, tunicates, sponges), but may exhibit spatial variation in its interactions with the community as growth and temperature can covary and influence competitive outcomes (Lord 2016). Ecological studies in California have been spatially limited to single locations, making it difficult to generalize the relationship between $W$. subtorquata abundance and community diversity and composition across environmental contexts. Considering these community patterns across broader spatial scales would improve our understanding of spatial variation of ecological effects of widespread influential species (Legendre et al. 2005). In this study, we ask: (1) What is the variance in diversity and community structure between regions within the California range of $W$. subtorquata? (2) How does $W$. subtorquata abundance differ between these environmental contexts? (3) Is W. subtorquata abundance related to patterns in community diversity and composition? and (4) Does the relationship between $W$. subtorquata abundance and community diversity differ between environments?

\section{Materials and methods}

We conducted surveys in marinas within two protected bays-Bodega Harbor, CA $\left(38^{\circ} 19^{\prime} 21.0^{\prime \prime} \mathrm{N}\right)$ and Alamitos Bay, CA $\left(33^{\circ} 44^{\prime} 58.4^{\prime \prime} \mathrm{N}\right)$ - in the northern and southern sea surface temperature regimes of California $\left(8-15^{\circ} \mathrm{C}\right.$ and 


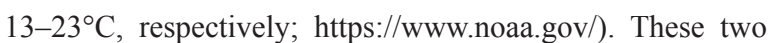
locations have documented presence of Watersipora subtorquata, and represent the cooler and warmer thermal regimes it experiences in its California range (Mackie et al. 2012). Bodega Harbor is mainly used for commercial fishing and research, while Alamitos Bay experiences heavy recreational boat traffic.

In July and August 2015, we used underwater photo surveys to examine public access docks (at least $90 \mathrm{~m}$ between dock sites in a harbor) in Alamitos Bay $(n=4)$ and Bodega Harbor $(\mathrm{n}=5)$ to determine the percent cover of $W$. subtorquata and characterize the fouling communities within harbors and between harbor environments. To conduct photo surveys, an underwater camera was attached to a polyvinyl chloride (PVC) frame to take digital photographs $0.2 \mathrm{~m}$ (lens to subject) from the underside of the dock at approximately $0.5 \mathrm{~m}$ depth below the water's surface. This allowed for equal area to be captured in each photo $\left(0.08 \mathrm{~m}^{2}\right.$ of the surface), and thirty photos were taken at each dock along a transect on the underside of the dock. These photosurveys are an efficient method for estimating species richness and abundance (Preskitt et al. 2004), and allow for consistent sampling among sites. Surveys initially included 5 sites per harbor, but one site in Alamitos Bay had to be dropped from analysis as the photos were insufficient for identifying species.

We analyzed photos using Coral Point Count with Excel extensions software (CPCe), which overlaid 75 points onto each image using the stratified random method (Kohler and Gill 2006). The stratified random method reduces the clumping of randomly distributed points by dividing the bordered area into rows and columns and populating each cell with an equal number of randomly distributed points (Kohler and Gill 2006). Each point in the photo was assigned to the species that it covered, a list of which was generated by keying out all organisms to the lowest possible taxonomic level using voucher specimens collected from the field and a taxonomic key (Carlton 2008). We used the data created by CPCe to quantify percent cover of each taxon, richness, and diversity (Shannon diversity index, $H^{\prime}$ ) for each quadrat within each site. Since some organisms could only be identified to genus, we consider richness as a measure of taxonomic richness; likewise, diversity was considered at the taxonomic level, which is likely an underestimate of species diversity.

\section{Analysis}

We examined the variance in $W$. subtorquata abundance and community diversity between harbors and among sites using generalized linear mixed models (GLMM) in SAS version 9.2 (SAS Institute Inc. 2008, Cary, NC). We included Harbor (Bodega vs. Alamitos) as a fixed factor and sites nested within harbor as a random effect. The significance of the random effect was tested with a likelihood ratio test. For each dependent variable, we used the error distribution with the lowest Akaike Information Criterion (AIC) value; this was Gamma distribution for percent cover, and Gaussian Distribution for diversity. The first GLMM tested the effects of harbor and sites on the abundance (percent cover) of $W$. subtorquata. The second GLMM examined the same effects on taxonomic diversity. To examine whether $W$. subtorquata abundance was associated with changes in community diversity, and whether that relationship differed between harbors or sites, we included $W$. subtorquata abundance as a covariate. AIC determined that a polynomial fit between the covariate and the dependent variable was better than a linear fit.

With the adonis function from the vegan package (Oksanen et al. 2015) in R (version 3.1.2, R Core Team 2016), we used a permutational analysis of variance (PERMANOVA) to compare dissimilarities in community composition both within and between harbors. Bray Curtis dissimilarities of squareroot transformed species proportion abundances were used in a similarity percentage analysis (SIMPER) to determine the extent to which the abundance of $W$. subtorquata and other community members contributed to the average dissimilarity in community composition between environments. Then, the compositional differences among communities were visualized using nonmetric Multidimensional Scaling (nMDS).

\section{Results}

In total, we identified 35 taxa of ascidians, bryozoans, sponges, algae, and gastropods at our sites. Most species on this list are sessile taxa, but we included three slow-moving gastropod species. In our photos, we could identify 20 taxa to species, and 14 to genus (Appendix 1); all turf algae were pooled into a single taxon. Watersipora subtorquata percent cover differed significantly across sites within harbors $(\mathrm{G}=$ 285.43, $\mathrm{P}<0.001$ ), and there was no statistical difference in W. subtorquata cover between harbors $\left(\mathrm{F}_{1,7}=0.3, \mathrm{P}=0.60\right.$; Fig. 1A). In Alamitos Bay, W. subtorquata average percent cover $( \pm \mathrm{SE})$ across all sites was $32.6 \pm 3.9 \%$, while the average percent cover among sites in Bodega Harbor was $17.8 \pm$ 3.0\%. Diversity differed significantly between harbors $\left(\mathrm{F}_{1,7}\right.$ $=8.06, \mathrm{P}=0.025$; Fig. 1B), with Bodega Harbor exhibiting a greater average $( \pm \mathrm{SE})$ diversity $\left(\mathrm{H}^{\prime}=1.0 \pm 0.05\right)$ than Alamitos Bay $\left(\mathrm{H}^{\prime}=0.81 \pm 0.05\right)$. Sites within harbors differed significantly $(\mathrm{G}=4.23, \mathrm{P}=0.040)$ and explained $10.1 \%$ of the variance in diversity.

The relationship between $W$. subtorquata abundance and community diversity differed significantly between harbors $\left(\mathrm{F}_{1,158}=7.2, \mathrm{P}=0.008\right.$; Fig. 2$)$. In Bodega Harbor, there was a significant polynomial relationship between $W$. subtorquata cover and diversity $\left(\mathrm{F}_{1,113}=20.4, \mathrm{P}<0.001\right.$; Fig. $\left.2 \mathrm{~A}\right)$, whereas there was no statistical relationship in Alamitos Bay $\left(\mathrm{F}_{1,45}=\right.$ $0.53, \mathrm{P}=0.47$; Fig. $2 \mathrm{~B})$. W. subtorquata abundance explained $25 \%$ of the variance in diversity in Bodega Harbor (Fig. 2A), and otherwise less abundant taxa such as bryozoans and tunicates exhibited greater richness in sites with a greater abundance of W. subtorquata (Appendix 1). In Alamitos Bay, sites with greater $W$. subtorquata abundance were associated with shifts in abundance of several bryozoan and tunicate species (Appendix 1).

PERMANOVA revealed that communities were significantly dissimilar between harbors, $(\mathrm{F}=15.6, \mathrm{P}<0.001$; Fig. 3). A test of homogeneity of multivariate dispersions 

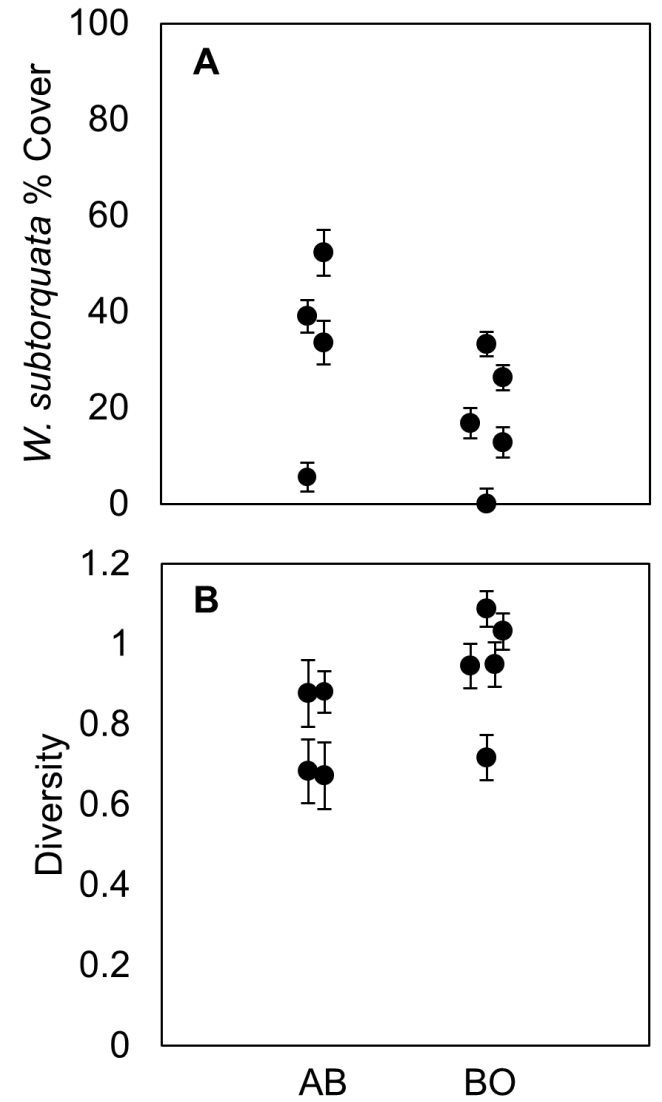

Figure 1. Mean ( \pm SE) A) W. subtorquata percent cover and B taxonomic diversity (Shannon, $H^{\prime}$ ) at sites within Alamitos Bay (AB) and Bodega Harbor (BO)

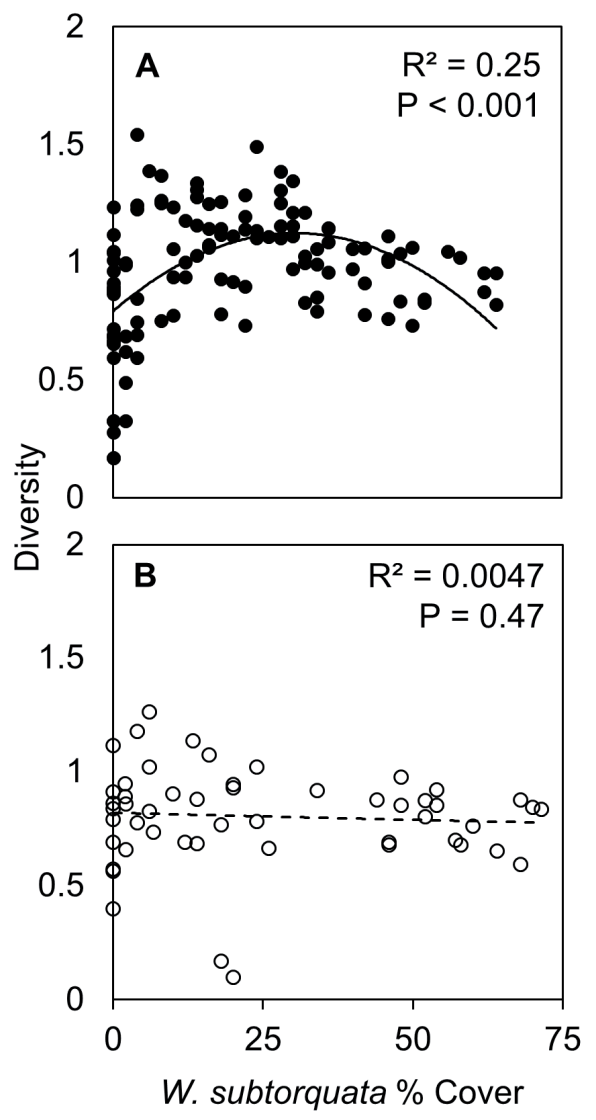

Figure 2. Relationship between W. subtorquata percent cover and taxonomic diversity (Shannon, $H^{\prime}$ ) for A) Bodega Harbor and B) Alamitos Bay. $\mathrm{R}^{2}$ and $\mathrm{P}$ values indicated on graphs.

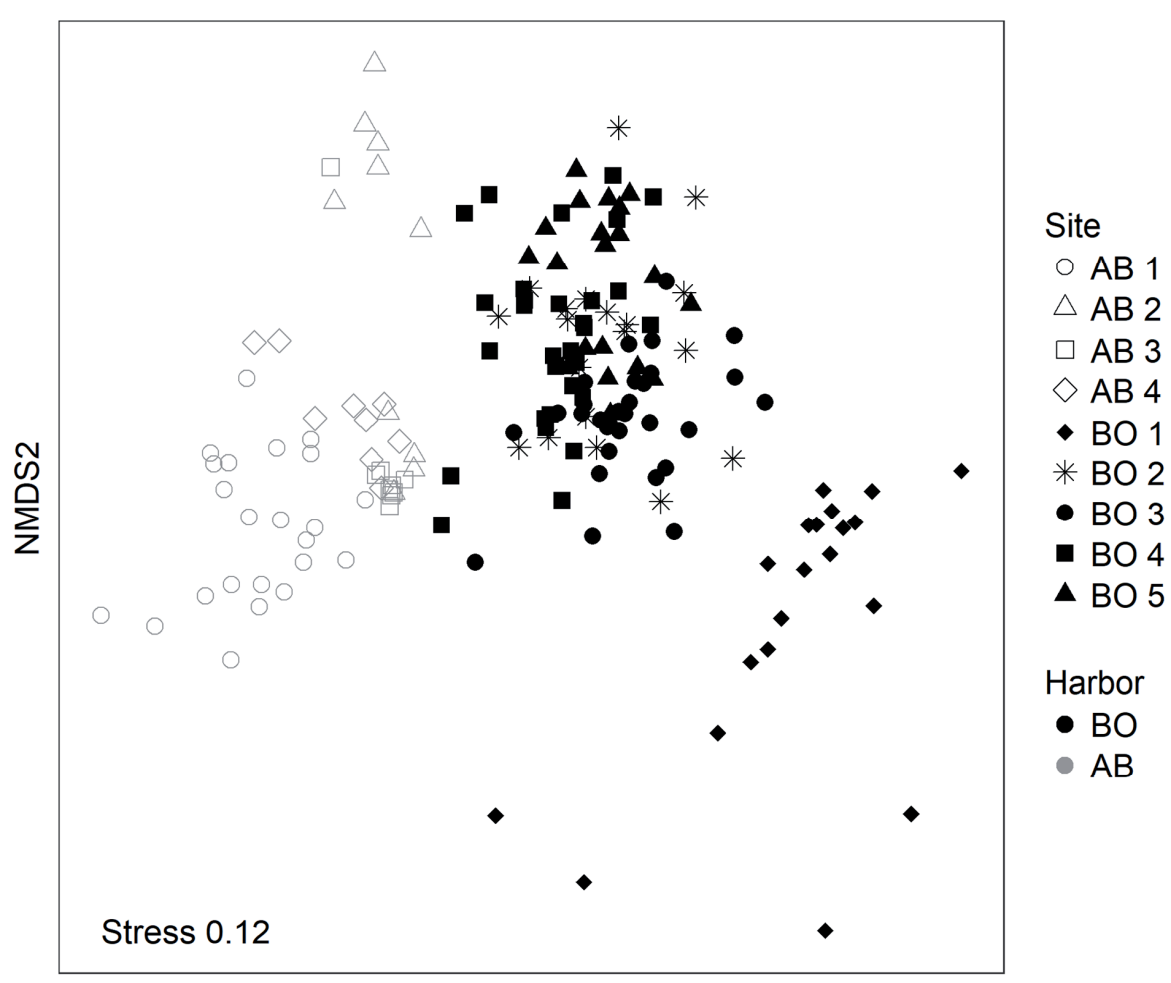

NMDS1
Figure 3. Nonmetric multi-dimensional scaling (nMDS) plot showing differences in community composition among sites within harbors. Each point represents a community (one photo quadrat), shapes represent sites, colors represent harbor environments. 
Table 1. Results from the SIMPER analysis performed with multivariate data from both Bodega (BO; $n=5$ sites) and Alamitos (AB; $n=$ 4 sites) to identify species contributing the most $(\geq 5 \%)$ to observed changes in community composition between harbor environments. Pooled across sites, means \pm SE for percent cover per species in each harbor environment are presented.

\begin{tabular}{llccc}
\hline \multicolumn{1}{c}{ Phylum } & \multicolumn{1}{c}{ Species } & Percent Cover (\%): BO & Percent Cover (\%): AB & Contribution (\%) \\
\hline Bryozoa & Watersipora subtorquata & $19.83 \pm 1.67$ & $18.82 \pm 2.35$ & 10.06 \\
Chordata & Didemnum lahillei & $11.06 \pm 1.86$ & 0 & 9.33 \\
Mollusca & Mytilus californianus & $2.33 \pm 0.85$ & $34.58 \pm 2.08$ & 8.16 \\
Chordata & Botrylloides violaceus & $9.50 \pm 0.32$ & $0.98 \pm 0.32$ & 6.18 \\
Bryozoa & Bugula neritina & $5.68 \pm 0.91$ & $0.16 \pm 0.089$ & 5.64 \\
\hline
\end{tabular}

confirmed that the average distances of communities to the median in both environments were not significantly different $(\mathrm{F}=2.4, \mathrm{P}=0.12)$. Alamitos Bay communities were primarily composed of bryozoans and tunicates, whereas Bodega Harbor communities were also dominated by bivalve taxa. Of the 35 taxa surveyed, only eight were present in both harbors, some of which were found in very low abundances (Appendix 1). Halichondria sp. (Porifera, Fleming, 1828) and Mytilus californianus (Mollusca, Conrad, 1837) were found in both harbors, but Halichondria sp. was more abundant in Bodega Harbor and M. californianus was more abundant in Alamitos Bay. W. subtorquata was the most common (present in $\geq 50 \%$ of quadrats) species across all sites, and SIMPER analyses revealed that $W$. subtorquata abundance had the highest percent contribution to dissimilarity among communities between environments (Table 1). Two invasive tunicates in Bodega Harbor, Didemnum lahillei (Hartmeyer, 1909) and Botrylloides violaceus (Oka, 1927), were among the top five contributors to community dissimilarity, as well as another invasive bryozoan, Bugula neritina (Linnaeus, 1758). While more commonly found in Alamitos Bay than in Bodega Harbor, Mytilus californianus (Mollusca) was also a top contributor to differences among communities.

\section{Discussion}

Within the California range of Watersipora subtorquata, communities both within and between the harbor environments differed in diversity and community composition, with Bodega Harbor exhibiting greater diversity and dissimilarity among communities. W. subtorquata was common in both harbors surveyed but exhibited significant variation in abundance (i.e., percent cover) among sites within harbors, though the two harbors did not differ in W. subtorquata abundance. However, the relationship between $W$. subtorquata abundance and diversity varied between harbors, suggesting that interactions between $W$. subtorquata and the community may differ between environments or community contexts. W. subtorquata abundance had the highest percent contribution to community dissimilarity relative to other community members. This suggests that the growth and spread of this species may have effects on the native community throughout its range as it competes for space on the substratum, especially as it has a strong overgrowth capability relative to other fouling community members (Edwards and Stachowicz 2010). However, this does not preclude that a correlation with an unmeasured variable and these variables may drive this association.

The significant nonlinear relationship between $W$. subtorquata abundance and community diversity in Bodega Harbor-but not in Alamitos Bay-suggests that W. subtorquata may have indirect or direct effects on species diversity or community structure in some environments, but not others (Fig. 2). As the dissimilarity of community composition between harbors is primarily driven by differences in the abundance of $W$. subtorquata, the effects on the community may be more at the level of taxonomic composition rather than diversity. This invader may be displacing some species while providing novel habitat or substrata for others, but the balance between facilitative and inhibitive effects differs between environments and across communities. At high abundances, $W$. subtorquata occupied space where other sessile species would have otherwise settled, and this trend was more apparent in Bodega Harbor where there was a low diversity of dominant species that compete for space. In comparison to other sessile colonial invertebrates in Bodega, W. subtorquata has a high overgrowth rank, as the live zooid modules may prevent settlement of other species (Edwards and Stachowicz 2010).

In Alamitos Bay, higher percent cover of W. subtorquata is associated with decreased percent cover of sessile tunicate species such as Botrylloides diegensis (Ritter \& Forsyth, 1917), Botrylloides violaceus, and Botryllus schlosseri (Pallas, 1766), and increased percent cover of bryozoans Cellaria spp. and Crisulipora occidentalis (Robertson, 1910, Appendix 1). A possible explanation for the lack of correlation between $W$. subtorquata percent cover and diversity in Alamitos may be that in this environment, $W$. subtorquata interacts with a greater diversity of species than in Bodega, so changes in its abundance, while appearing to not affect diversity, may in fact alter the composition. The positive effects on some species appear to be balanced by negative effects on others. In Bodega Harbor, low W. subtorquata percent cover is associated with increased diversity, where it may still provide important settlement substrate, but is associated with declining diversity at higher abundances, where competition for space is more likely among the few dominant species. These results, however, represent relatively short-term dynamics, and more long-term monitoring studies of fouling communities have found evidence of greater variation in both $W$. subtorquata cover and community diversity (Marasinghe et al. 2018). 
W. subtorquata can serve as a non-toxic settlement substratum for bryozoans, polychaetes, and amphipods that are sensitive to antifouling paints (Floerl et al. 2004), and thus may act as a foundation species and have a net positive effect on many species. Additionally, the structural complexity of larger, foliose colonies of $W$. subtorquata may provide additional attachment sites for sessile species, compensating for the space occupied on the substratum (Stachowicz and Byrnes 2006). Though there are few examples of sessile invertebrates settling directly on $W$. subtorquata (Sellheim et al. 2009, Davis and Marshall 2014), a demosponge, Halichondria sp. (Porifera) was found to grow directly on W. subtorquata colonies in Bodega Harbor (pers. obs.), suggesting it has the potential to serve as novel habitat for other species. While W. subtorquata is a weaker competitor in the short time after recruitment to the substratum, it grows into larger foliose colonies through time and may be more competitive in these older, more dense stands (Edwards and Stachowicz 2010).

Though these results highlight a relationship between $W$. subtorquata abundance and diversity in some contexts, the low explanatory power of $W$. subtorquata abundance for differences in diversity - especially in Alamitos Bay_indicates that other important factors may explain more of the variance in diversity. Alamitos Bay communities were dominated by tunicate and bryozoan species (Appendix 1), several of which were not present at sites with high $W$. subtorquata abundance, suggesting that $W$. subtorquata may compete strongly for space with other colonially-growing organisms. However, the increased abundance of some bryozoan and algal taxa suggests indirect or direct facilitation by $W$. subtorquata (Appendix 1). Thus, the net effect on diversity with relation to $W$. subtorquata cover did not differ from zero.

Other factors such as resource and nutrient availability, flow patterns (Palardy and Witman 2014), and temperature (Lord 2016) can substantially influence community structure and diversity, and may better explain the observed patterns than differences in $W$. subtorquata abundance across sites surveyed within the harbor environments. These variables were not monitored during the present study, but would certainly improve explanation of the presented findings. Bodega Harbor and Alamitos Bay represent different thermal regimes $\left(12-13^{\circ} \mathrm{C}\right.$ and $17-18^{\circ} \mathrm{C}$, respectively) that $W$. subtorquata experiences within its range along California's coast, and the seasonal variability in temperatures may contribute to differences in diversity and community structure both within and between harbors.

Furthermore, the two harbors differ in their primary uses and activities. Bodega Harbor is primarily used for commercial and recreational fishing vessels, and live-aboard boats at their docks, both of which can have longer residence times in the harbor and could increase competition for space among fouling invertebrates. Alamitos Bay has more recreational activities such as kayaking, stand-up paddle boarding, and publicly-accessible docks, which may contribute to increased disturbance of the docks and settlement substrate. This increased level of disturbance may contribute to greater diversity as open patches of space are created that promote high diversity because of a reduction in the likelihood of competitive exclusion (Willig and Presley 2018). Though these factors were not surveyed or included in analyses for the present study, they could help explain the variance in community parameters between harbors in addition to the abiotic factors mentioned above.

The importance of foundation species in ecosystems has been well established in ecology (Dayton 1972, Stachowicz 2001), but the concept of an invasive species exhibiting the same positive effects associated with foundation species on a community is less well studied (Rodriguez 2006). Though invasive foundation species may provide novel habitat in comparison with native foundation species, they should be less important than native foundation species since they did not coevolve with others in the community. Communities without the invader should have greater diversity, though we were not able to test this hypothesis in our study. Historically, invasive species and foundation species have been thought to have opposing effects on communities, but only recently have ecologists considered species that might fulfill both roles simultaneously (Rodriguez 2006). Examples of invasive foundation species exist in mixed Eastern Caribbean seagrassmollusc and seagrass habitats (Willette and Ambrose 2012, Thomsen et al. 2013) and fouling communities on docks in Bodega Harbor, CA (Sellheim et al. 2009). Our study suggests that $W$. subtorquata has the potential to interact with the community as a foundation species by influencing both the diversity and community composition of sessile fouling invertebrates throughout its California range. The complex morphology of these colonies may act as settlement substrata for species that prefer complex habitat. These surveys did not, however, include mobile species that may show different patterns of abundance and diversity (Sellheim et al. 2009), as the structurally complex colonies create many crevices and spaces that can serve as important and novel habitat or refuge from mobile predators for smaller $(\leq 2 \mathrm{~cm})$ invertebrates such as polychaetes and crustaceans. Considering the variation in the effects of invasive foundation species not only across environments in their invasive range, but also across communities with different compositions, can provide insights into the complex processes and species interactions that shape diverse communities over spatial scales.

Acknowledgements. The authors wish to acknowledge graduate students and staff from both California State University, Long Beach and the University of California Davis Bodega Marine Laboratory for field assistance and diving support. We thank M. Whalen and J. Stachowicz for logistical support and advice. We also thank P. J. Edmunds and two anonymous reviewers for comments on the manuscript. Funding was provided by the California State University Thesis Support Program, Graduate Equity Fellowship, and Outstanding Graduate Promise Award, the California State University Council on Ocean Affairs, Science \& Technology Graduate Student Research Award, and the National Science Foundation under grants DMS1312490 and OCE-1559105. 


\section{Conflict of interest}

The authors have no conflict of interest to report.

\section{Author contributions}

ZRS designed and conducted the field surveys, completed data analysis, and wrote the manuscript. CPT assisted with the experimental design and edited the manuscript.

\section{References}

Angelini, C. and B.R. Silliman. 2014. Secondary foundation species as drivers of trophic and functional diversity: Evidence from a tree-epiphyte system. Ecology 95:185-196.

Bax, N., A. Williamson, M. Aguero, E. Gonzalez and W. Geeves. 2003. Marine invasive alien species: a threat to global biodiversity. Mar. Policy 27:313-323.

Bertness, M.D. and R. Callaway. 1994. Positive interactions in communities. Trends Ecol. Evol. 9:187-191.

Bruno, J.F., J.J. Stachowicz and M.D. Bertness. 2003. Inclusion of facilitation into ecological theory. Trends Ecol. Evol. 18:119-125.

Carlton, J.T. 2009. Deep invasion ecology and the assembly of communities in historical time. In: Rilov, G. and Crooks, J. A. (eds), Biological Invasions in Marine Ecosystems - Ecological, Management and Geographic Perspectives. Springer, Berlin. pp. 13-56.

Carlton, J.T. 2008. The Light and Smith Manual: Intertidal Invertebrates from Central California to Oregon. Q. Rev. Biol. 83:130-130.

Cifuentes, M., I. Krueger, C.P. Dumont, M. Lenz and M. Thiel. 2010. Does primary colonization or community structure determine the succession of fouling communities? J. Exp. Mar. Bio. Ecol. 395: $10-20$.

Colautti, R.I. and H.J. MacIsaac. 2004. A neutral terminology to define 'invasive' species. Divers. Distrib. 10:135-141.

Crooks, J.A. 2002. Characterizing ecosystem-level consequences of biological invasions: the role of ecosystem engineers. Oikos 2: 153-166.

Crowl, T.A., T.O. Crist, R.R. Parmenter, G. Belovsky and A.E. Lugo. 2008. The spread of invasive species and infectious disease as drivers of ecosystem change. Front. Ecol. Environ. 6:238-246.

Davis, K. and D.J. Marshall. 2014. Offspring size in a resident species affects community assembly. J. Anim. Ecol. 83:322-331.

Dayton, P.K. 1972. Toward an understanding of community resilience and the potential effects of enrichment to the benthos at McMurdo Sound, Antarctica. Proc. Colloq. Conserv. Probl. Antarct. 81-96.

Dayton, P.K. and R.R. Hessler. 1972. Role of biological disturbance in maintaining diversity in the deep sea. Deep Sea Res. Oceanogr. Abstr. 19:199-208.

Edwards, K.F. and J.J. Stachowicz. 2010. Multivariate trade-offs, succession, and phenological differentiation in a guild of colonial invertebrates. Ecology 91:3146-3152.

Edwards, K.F. and J.J. Stachowicz. 2012. Temporally varying larval settlement, competition, and coexistence in a sessile invertebrate community. Mar. Ecol. Prog. Ser. 462:93-102.

Floerl, O., T. Pool and G. Inglis. 2004. Positive interactions between nonindigenous species facilitate transport by human vectors. Ecol. Appl. 14:1724-1736.
Gittenberger, A. 2009. Invasive tunicates on Zeeland and Prince Edward Island mussels, and management practices in The Netherlands. Aquat. Invasions 4:279-281.

Gittenberger, A. 2007. Recent population expansions of non-native ascidians in The Netherlands. J. Exp. Mar. Bio. Ecol. 342:122126.

Graebner, R.C., R.M. Callaway and D. Montesinos. 2012. Invasive species grows faster, competes better, and shows greater evolution toward increased seed size and growth than exotic noninvasive congeners. Plant Ecol. 213:545-553.

Graham, M.H. 2004. Effects of local deforestation on the diversity and structure of Southern California giant kelp forest food webs. Ecosystems 7:341-357.

Holbrook, S.J., A.J. Brooks, R.J. Schmitt and H.L. Stewart. 2008. Effects of sheltering fish on growth of their host corals. Mar. Biol. 155:521-530.

Hughes, B.B. 2010. Variable effects of a kelp foundation species on rocky intertidal diversity and species interactions in central California. J. Exp. Mar. Bio. Ecol. 393:90-99.

Knight, N.S., C. Prentice, M. Tseng and M.I. O’Connor. 2015. A comparison of epifaunal invertebrate communities in native eelgrass Zostera marina and non-native Zostera japonica at Tsawwassen, BC. Mar. Biol. Res. 11:564-571.

Kohler, K.E. and S.M. Gill. 2006. Coral Point Count with Excel extensions (CPCe):A Visual Basic program for the determination of coral and substrate coverage using random point count methodology. Comput. Geosci. 32:1259-1269.

Legendre, P., D. Borcard and P.R. Peres-Neto. 2005. Analyzing beta diversity: Partitioning the spatial variation of community composition data. Ecol. Monogr. 75:435-450.

Levine, J.M., P.B. Adler and S.G. Yelenik. 2004. A meta-analysis of biotic resistance to exotic plant invasions. Ecol. Lett. 7:975-989.

Lockwood, J.L., M.F. Hoopes, M.P. Marchetti. 2013. Invasion Ecology. Blackwell Publishing, Malden, USA.

Lord, J., R. Whitlatch and E.D. Grosholz. 2015. Predicting competitive shifts and responses to climate change based on latitudinal distributions of species assemblages. Ecology 96:1264-1274.

Lord, J.P. 2016. Temperature, space availability, and species assemblages impact competition in global fouling communities. Biol. Invasions.

Mackie, J.A., M.J. Keough and L. Christidis. 2006. Invasion patterns inferred from cytochrome oxidase I sequences in three bryozoans, Bugula neritina, Watersipora subtorquata, and Watersipora arcuata. Mar. Biol. 149:285-295.

Mackie, J.A, J.A. Darling and J.B. Geller. 2012. Ecology of cryptic invasions: latitudinal segregation among Watersipora (Bryozoa) species. Sci. Rep. 2:871.

Marasinghe, M.M.K.I., R.R.M.K.P. Ranatunga and A.C. Anil. 2018. Settlement of non-native Watersipora subtorquata (d'Orbigny, 1852) in artificial collectors deployed in Colombo Port, Sri Lanka. BioInvasions Rec. 7(1):7-14

McCuller, M.I. and J.T. Carlton. 2018. Transoceanic rafting of bryozoa (Cyclostomata, cheilostomata, and ctenostomata) across the north pacific ocean on Japanese tsunami marine debris. Aquat. Invasions 13(1):137-162.

McKenzie, L.A, R. Brooks and E.L. Johnston. 2011. Heritable pollution tolerance in a marine invader. Environ. Res. 111:926-32.

Mckenzie, L.A., R.C. Brooks and E.L. Johnston. 2012. A widespread contaminant enhances invasion success of a marine invader. $J$. Appl. Ecol. 49:767-773.

Miranda, A.A., A.C.S. Almeida and L.M. Vieira. 2018. Non-native marine bryozoans (Bryozoa: Gymnolaemata) in Brazilian wa- 
ters: Assessment, dispersal and impacts. Mar: Pollut. Bull. 130: 184-191.

Oksanen, J., F.G. Blanchet, R. Kindt, P. Legendre, R.B. O'Hara, G.L. Simpson, P. Solymos, M.H.H. Stevens and H. Wagner. 2015. vegan: Community Ecology Package. R package version 2.5-1. https://CRAN.R-project.org/package=vegan

Palardy, J.E. and J.D. Witman. 2014. Flow, recruitment limitation, and the maintenance of diversity in marine benthic communities. Ecology 95:286-297.

Parker, I., D. Simberloff and W. Lonsdale. 1999. Impact: toward a framework for understanding the ecological effects of invaders. Biol. Invasions 1:3-19.

Posey, M.H. 1988. Community changes associated with the spread of an introduced seagrass, Zostera japonica. Ecology 69(4):974983.

Power, M.E., D. Tilman, J.A. Estes, B.A. Menge, W.J. Bond, L.S. Mills, G. Daily, J.C. Castilla, J. Lubchenco and R.T. Paine. 1996. Challenges in the quest for keystones. Bioscience 46:609-620.

Preskitt, L.B., P.S. Vroom and C.M. Smith. 2004. A Rapid Ecological Assessment (REA) quantitative survey method for benthic algae using photoquadrats with scuba. Pacific Sci. 58:201-209.

R Core Team (2016). R: A language and environment for statistical computing. R Foundation for Statistical Computing, Vienna, Austria. URL https://www.R-project.org/.

Rodriguez, L.F. 2006. Can invasive species facilitate native species? Evidence of how, when, and why these impacts occur. Biol. Invasions 8:927-939.

Rohr, J.R., C.G. Mahan and K.C. Kim. 2009. Response of arthropod biodiversity to foundation species declines: The case of the eastern hemlock. For. Ecol. Manage. 258:1503-1510.

Ryland, J.S. and P.J. Hayward. 1991. Marine flora and fauna of the northeastern United States: Erect Bryozoa. NOAA Tech. Rep. NMFS. 99:1-48.

Sellheim, K., J.J. Stachowicz and R.C. Coates. 2009. Effects of a nonnative habitat-forming species on mobile and sessile epifaunal communities. Mar. Ecol. Prog. Ser. 398:69-80.

Simberloff, D. 1995. Why do introduced species appear to devastate islands more than mainland areas? Pacific Sci. 49:87-97.

Sorte, C.J.B., S.L. Williams and R.A. Zerebecki. 2010. Ocean warming increases threat of invasive species in a marine fouling community. Ecology 91:2198-2204.

Stachowicz, J.J. 2001. Mutualism, facilitation, and the structure of ecological communities. Bioscience 51:235-246.

Stachowicz, J.J., J.F. Bruno and J.E. Duffy. 2007. Understanding the effects of marine biodiversity on communities and ecosystems. Annu. Rev. Ecol. Evol. Syst. 38:739-66.
Stachowicz, J.J. and J.E. Byrnes. 2006. Species diversity, invasion success, and ecosystem functioning: Disentangling the influence of resource competition, facilitation, and extrinsic factors. Mar Ecol. Prog. Ser. 311:251-262.

Stachowicz, J.J., J.R. Terwin, R.B. Whitlatch and R.W. Osman. 2002. Linking climate change and biological invasions: Ocean warming facilitates nonindigenous species invasions. Proc. Natl. Acad. Sci. U. S. A. 99:15497-500.

Thomsen, M.S., P.A. Stæhr, L. Nejrup and D.R. Schiel. 2013. Effects of the invasive macroalgae Gracilaria vermiculophylla on two co-occurring foundation species and associated invertebrates. Aquat. Invasions 8:133-145.

Thomsen, M.S., T. Wernberg, P.M. South and D.R. Schiel. 2016. Non-native seaweeds drive changes in marine coastal communities around the world. In: Hu, Z.M. and Fraser, C. (eds), Seaweed Phylogeography. Springer, Dordrecht. pp. 147-186.

Van Kleunen, M., E. Weber and M. Fischer. 2010. A meta-analysis of trait differences between invasive and non-invasive plant species. Ecol. Lett. 13(2):235-45.

Vieira, L., M. Jones and P. Taylor. 2014. The identity of the invasive fouling bryozoan Watersipora subtorquata (d'Orbigny) and some other congeneric species. Zootaxa 3857:151-182.

Willette, D.A. and R.F. Ambrose. 2012. Effects of the invasive seagrass Halophila stipulacea on the native seagrass, Syringodium filiforme, and associated fish and epibiota communities in the Eastern Caribbean. Aquat. Bot. 103:74-82.

Willig, M.R. and S.J. Presley. 2018. Biodiversity and disturbance. Encyclopedia of the Anthropocene 3:45-51.

Wyatt, A.S.J., C.L. Hewitt, D.I. Walker and T.J. Ward. 2005. Marine introductions in the Shark Bay World Heritage Property, Western Australia: A preliminary assessment. Divers. Distrib. 11:33-44.

York, P., P. Evangelista, S. Kumar, J. Graham, C. Flather and T. Stohlgren. 2011. A habitat overlap analysis derived from maxent for tamarisk and the south-western willow flycatcher. Front. Earth Sci. 5:120-129.

Zerebecki, R.A. and C.J.B. Sorte. 2011. Temperature tolerance and stress proteins as mechanisms of invasive species success. PLoS One 6:e14806

Received June 28, 2019

Revised September 28, November 1, 2019

Accepted November 12, 2019

Appendix 1. Cumulative list of taxa found at sites across harbor environments. The file may be downloaded from www.akademiai.com 